DOI 10.37882/2223-2974.2020.11.22

\title{
НАПРАВЛЕННОСТЬ РАЗВИТИЯ ИННОВАЦИОННЫХ ПРЕДПРИЯТИЙ АПК: СОВРЕМЕННЫЕ АСПЕКТЫ И ВОЗМОЖНЫЕ ПЕРСПЕКТИВЫ
}

\section{FUNCTIONING AND DEVELOPMENT OF ENTERPRISES PRODUCING INNOVATIVE MACHINERY AND EQUIPMENT FOR THE AGRO-INDUSTRIAL COMPLEX: ASPECTS OF THE CURRENT CONFIGURATION AND POSSIBLE PROSPECTS}

\section{N. Lebedev}

G. Loktionova

Summary: The article analyzes the structural guidelines of enterprises that produce innovative machinery and equipment for the agro-industrial complex, as well as some types of products that are innovative in nature. Separate tasks of digitalization for the development of production of unmanned vehicles are considered, taking into account the potential growth of consumption of livestock products.

It is concluded that for the further development of enterprises producing innovative machinery and equipment for the agro-industrial complex, it is necessary to give priority to their development strategy, which should be based on clear guidelines for the long-term period.

Keywords: agricultural products market, investment, innovative equipment, competitiveness, innovation, rural infrastructure.
$\Phi$ ункционирование и развитие предприятий, производящих инновационную технику и оборудование для АПК, ориентированы на технологические инновации, которые обеспечивают совершенствование отраслевых технологий. Понятно, что конкурентоспособность отечественных научных технологий, направленных на повышение эффективности предприятий АПК обеспечивается в т.ч. и законодательством, фиксирующим на обозримую перспективу направленность инновационных технологий, рынка не только высокопродуктивного, но и экологичного агрохозяйства и т.п. [1]; обеспечения совершенствования отраслевых технологий как и функционирование и развитие предприятий сельскохозяйственного машиностроения в целом диктуется и необходимостью роста обеспечения техникой сельскохозяйственных акторов, остающейся пока ещё на недостаточном уровне. Так, в среднесрочной перспективе энергообеспеченность на один гектар пашни в среднем составляет 1,5 лошадиных силы, при том, что в Белоруссии энергообеспеченность достигла 5,0 л.с. как
Лебедев Никита Андреевич

Д.э.н., профессор, ФГБОУВО «Московская государственная академия ветеринарной медицины и биотехнологии имени К.И. Скрябина» swonson@bk.ru

Локтионова Галина Робертовна

К.с.-Х.н., дочент, ФГБОУ ВО «Московская государственная академия ветеринарной медицины и биотехнологии имени К.И. Скрябина» galina.lokti@yandex.ru

Аннотация: Проанализированы структурные ориентиры предприятий, производящих инновационную технику и оборудование для АПК, некоторые виды продукции, носящие инновационный характер.

Рассмотрены отдельные задачи цифровизации по развитию производства беспилотной техники сучётом потенциального роста потребления продукции животноводства.

Сделан вывод, что для дальнейшего развития предприятий, производящих инновационную технику и оборудование для АПК необходимо придать опережающее развитие стратегии их развития, которая должна основываться на чётких ориентирах на долгосрочный период.

Ключевые слова: рынок агропродукции, инвестиции, инновационная техника, конкурентоспособность, инновации, сельская инфраструктура.

и в среднем по Евросоюзу. Возрастная структура эксплуатации парка техники для АПК с большими усилиями отвечает требованиям момента, составив, в частности, в 2019 году по тракторам до 3-х лет- 12\%; от 3-х до 10-ти лет - 28\%; более 10 лет - 60\% [2].

В определённой мере данная ситуация может объясняться духом реформаторства 90-х годов XX в. и его негативными последствиями, что отразилось на выпуске инновационной техники и оборудования для АПК, когда отраслевое производство сократилось к 2013 году по комбайнам в пятнадцать, а по сельскохозяйственным тракторам - более, чем в двести раз лишь с 90-х гг.

В свою очередь, со временем рентабельность предприятий, производящих технику и оборудование для АПК возрастала, снижалась численность убыточных предприятий, оптимизировались финансы большинства из них, постепенно стала концентрироваться активность отрасли, что было связано, прежде всего, с ростом инве- 
стиционного спроса, экспорта, тогда как, в частности, машиностроение для АПК в структуре продукции отрасли составило примерно 4 \%. В частности, в 2019 г. было отгружено техники и оборудования для АПК на 105,7 млрд. рублей, или на 5\% больше предыдущих показателей; поставлено 165 моделей, или на 2\% больше, чем в предыдущем периоде.

География предприятий показывает, что более 80 \% технической продукции и оборудования для АПК производится на предприятиях в Центре, в Волго-Вятском, Уральском и Поволжском округах с применением многофункциональной специализации, поставляя на рынок продукцию разнообразных модификаций, различное оборудование.

В частности, В состав ассоциации «Росспецмаш» в июне 2018 г., как показывает Интернет-портал «Росспецмаш-Стат», входило 152 компании, поставляющих на рынок агропродукцию и оборудование, которые в 2018 г. довели долю отечественных моделей до 60\% [6]. В свою очередь, в 2019 г. техники и оборудования для АПК было отгружено на 101,2 млрд руб. Если до 2024 года по программе № 1432, возможно, поступит 16,5 млрд руб., то уровень модернизации предприятий, производящих инновационную технику и оборудование для АПК снижены не будут.

Законом «О федеральном о бюджете» на 2020-2021 гг. для реализации Госпрограммы АПК выделено 306 110, 45 млн руб. [3], а инвестиции в основной капитал по сельскому хозяйству достигли за первое полугодие 2019 г. - 195 млрд руб. [4].

В России выпускают достаточно широкий ассортимент продукции такие крупные производители техники и оборудования для АПК как «Тракторные заводы» и «Ростсельмаш», формируя глубокую дифференциацию отрасли и воздействуя на размещение продукции.

В частности, «Ростсельмаш», поставляет АПК сельхозтехнику в сортаменте - от многопрофильных комбайнов до тракторов; «Ростсельмаш» выпускает трактора Rostselmash Versatile, заниает около 70\% отечественного и около 17\% мирового рынка зерноуборочных комбайнов. При этом, постепенное сворачивание программы поддержки сельхозмашиностроения привело к тому, что к 2019 году отечественный рынок сузился.

Но, несмотря на это, к 2024 году «Ростсельмаш» планирует разместить ряд проектов, в общей сложности вложив в уникальные производства не менее 17 млрд рублей и ввести в эксплуатацию предприятие в Ростовена-Дону, которое обеспечит хозяйства 26-ю новыми модификациями и моделями инновационной техники для АПК. Кроме того, в планах запуск нового комплекса по окрашиванию техники, обладающего добавочным уровнем стойкости быстросохнущей эмали широкой цветовой гаммы полиуретаново-эпоксидной композиции с изоцианатным отвердителем, что повысит качество продукции и объём её реализации. Ключевым условием развития предприятий, производящих инновационную технику и оборудование для АПК становится производство многоступенчатой трансмиссии третьего поколения на основе технической документации японского концерна «Jatco».

На рынке представлен и завод «Агромаш», входящий в объединение «Тракторные заводы», выпускающий, в частности, такие тракторы как «Агромаш-180ТК», комбайны «Енисей 950», «Агромаш 5000».

Со своей стороны, заводы «Агротехмаш» и Terrion, расположенные в Санкт-Петербурге и Тамбове соответственно, собирают комбайны, тракторы АТМ 7360 Terrion, различную спецтехнику. Примечательно, что широкий сортимент техники предлагает к реализации тракторный завод в Набережных Челнах.

Наблюдается незначительный рост объёма производства на Волгоградском тракторном заводе (представлен «ОАО ВгТЗ»), на котором внедряют новые технологии, разработанные под цикл производства ВТЗ, где в 2020 году предложены рынку обновлённые модели высокопроизводительных бульдозеров и тракторов.

Завод специализированной сельхозтехники «Петра» (С.-Петербург) выпускает тракторы «Петра», строительную, дорожную и уборочную технику - машины «УДМ», снегоочистители, погрузчики, тракторы «К-700».

Таблица. 1.

Базовые виды техники сельскохозяйственного назначения, тыс. шт.

\begin{tabular}{|l|c|c|c|c|c|}
\multicolumn{1}{|c|}{ Виды техники } & 2015 г. & 2016 г. & 2017 г. & 2018 г. & 2019 г. \\
\hline Тракторы & 233,6 & 223,4 & 216,8 & 211,9 & 206.7 \\
\hline $\begin{array}{l}\text { Зерноуборочные } \\
\text { комбайны }\end{array}$ & 64,1 & 61,6 & 59,7 & 56,9 & 55,0 \\
\hline $\begin{array}{l}\text { Картофелеуборочные } \\
\text { комбайны }\end{array}$ & 2,3 & 2,2 & 2,1 & 2,0 & 2,0 \\
\hline $\begin{array}{l}\text { Кормоуборочные } \\
\text { комбайны }\end{array}$ & 14,0 & 13,3 & 12,7 & 12,3 & 11,8 \\
\hline
\end{tabular}

По данным Росстата

Количественный рост продемонстрировал производство техники, в частности, разбрасывателей удобрений, производство которых, в частности, в 2017 году достигло 571 тысяч, а в 2018 году - 808 тыс. единиц [5]. В целом парк базовых видов техники ограничен, как правило, из-за снижения уровня потребительских доходов 
(табл.1).

Соответственно, в 2019 г. и закупки базовых видов сельскохозяйственной техники сельскохозяйственными структурами были также свёрнуты - на падении закупок базовых видов техники сказалось снижение реальных доходов фермеров. Затягивалась выплата субсидий и льготных кредитов на приобретение сельскохозяйственными организациями базовых видов техники. Со своей стороны, в 2018 г. из федерального бюджета на поддержку агропромышленного комплекса выделено дополнительно около 10 млрд руб., а на поддержку агропромышленных хозяйств - три млрд руб. [6]. Хозяйства закупили комбайнов - 5,2 тыс., комбайнов кормоуборочных - 646 и тракторов - 10,4 тыс. - субсидии благоприятствовали закупке 65\% зерноуборочных комбайнов, 12 \% тракторов, 31 \% кормоуборочных комбайнов [7].

На реализацию программ развития с 2013 года предприятиям было отпущено 18,4 млрд рублей субсидий, в итоге потребители закупили сельхозтехники на 81,5 млрд руб. [8]. Так, Петербургскому тракторному заводу только в период 2017- 2019 гг. были выделены инвестиции в сумме 400 млн руб. на диверсификацию и развитие производства, что стало обоснованным шагом, т. к. ключевой продукцией этого предприятия остаются дорожные машины, фронтальные погрузчики, бульдозеры, самосвалы, роторные снегоочистители [9].

На развитие предприятий, производящих инновационную технику и оборудование для АПК в 2019 г. из бюджета предоставлено скидок на сумму 8 млрд руб., однако, как отмечалось, уровень этого содействия сокращается - вместо программы № 1432 внедряются лизинговые схемы - так, в 2019 г. финансовая поддержка по передаче в лизинг сельскохозяйственной техники у АО «Рослизинг» превысило 20 млрд руб., что на 70\% выше показателей 2018 г. Однако, для реализации сельхозтехники по лизингу только до 2025 г. потребуется выделения из федерального бюджета примерно 500 -т млрд руб.

Анализ проблемы показывает, что в направлении сокращения корректируются и программы господдержки сельскохозяйственного машиностроения. Так, отменён обратный выкуп, предусмотренный постановлением № 1269 , что давало возможность заменять сельхозтехнику уже бывшую в употреблении, что, прежде всего, интерпретировалось сезонной волатильностью спроса на технику и оборудование.

Вместе с тем, в аспекте рассматриваемой темы не менее важным сегментом следует обозначить изобретения, относящиеся к инновационной технике и оборудованию для АПК, в частности, К оборудованию, способствующему созданию микроклимата в сельскохозяйственных помещениях. Так, разработана термоэлектрическая уста- новка по осушению воздуха в сельскохозяйственных помещениях, содержащая термоэлектрический блок с включённым в него жидкостными теплообменниками горячего и холодного спаев и помещённых между ними, кроме электровентилятора, термоэлектрических модулей, пластинчатых теплообменников горячего и холодного контуров по обработке воздуха. Её инновационность состоит в том, что жидкостные теплообменники холодного и горячего спаев и находящиеся между ними термоэлектрические модули Пельтье располагаются в теплоизолированном блоке и соединяются с пластинчатыми теплообменниками горячего и холодного контуров, которые объединены с электровентилятором в общий корпус-трубу, который, в свою очередь, расположен В помещении сельскохозяйственного назначения, и при этом теплообменник холодного спая соединяется через циркуляционный насос трубопроводом холодного контура с теплообменником холодного контура, что образует замкнутый контур, а теплообменник горячего спая соединён через циркуляционный насос трубопроводом горячего контура с пластинчатым теплообменником горячего контура, что также образует замкнутый контур [10], при этом термоэлектрический блок отдельно теплоизолирован и установлен вне сельскохозяйственного помещения [11]. Термоэлектрическая установка повышает эффективность и надёжность устройства за счёт того, что увеличен её холодильный коэффициент [12].

В аспекте важности предстоящего приращения производственных и экономических показателей, оптимистичный сценарий развития предприятий, производящих инновационную технику и оборудование для АПК, может быть исполнен в ситуации, при которой уровень производства с течением времени будет нарастать: ожидается, что в 2020 г. он составит 136 млрд руб., а в 2025 г. планируется на уровне около 240 млрд руб. Предвидится прирост экспорта техники и оборудования, в частности, в 2020 году он может составить 17 млрд руб., в 2021 году - 19 млрд руб., в 2025 г. - до 30 млрд руб., при этом в 2019 году экспорт составлял 13 млрд руб. Что же касается такого не менее важного показателя как доля импорта сельхозтехники, то в 2020 году её планируют на уровне 24\%, в 2025 году - около 20\% [13]. Опять же, по оптимистическому сценарию, предприятия нарастят производство тракторов средней и малой мощности, производство техники для культивирования льна, конопли, для животноводства овощеводства, садоводства.

Оптимистический сценарий развития заложен и в технологии решения проблем сельскохозяйственного машиностроения как отрасли - в Стратегии развития сельхозмашиностроения, где предусмотрено, что к 2021 г. предложение инновационной техники и оборудования для АПК увеличится почти вдвое, тогда как к 2030 году - в три раза; объём экспорта должен составить около ста млрд руб. 
Как структурный ориентир модернизации предприятий, производящих инновационную технику и оборудование для АПК заявлена цифровизация аграрной техники, что не может не стать актуальным трендом, не может не увеличить производство сельхозтехники, обладающей искусственным интеллектом, машинным зрением, с автономной техникой. Но как воплотить заданный формат в рамках политики рыночного фундаментализма (свободного рынка), когда поддерживается ситуация, которой налогообложение сельскохозяйственных предприятий возвели в авторитет, когда растут проценты за кредиты для аграриев при их затратах на ресурсы, что, кстати, тормозит в т.ч. и решение задач по импортозамещению.

Но если ответственно решать вопрос цифровизации предприятий сельхозмашиностроения, то необходимо дать ответ на вопрос: возможна ли реализация программы «Цифровая экономика Российской Федерации» сообразно тренду «Цифровое сельское хозяйство» и что хотя бы по минимуму технически требуется для решения задачи? Как представляется, конечно же, требуется наладить выпуск беспилотной техники для землеобработки - в частности, контролирующей диагностику состояния как растений, так и животных, дронов-опрыскивателей и т.п., особенно в контексте потенциального прироста производства и потребления животноводческой продукции, и следуя необходимости роста урожайности, введения в сельхозоборот, согласно заявлению премьер-министра М. Мишустина, 12 млн га. необрабатываемой пашни по индивидуальным программам, на что выделено 14 млрд руб.[14].

Вместе с тем, шаг в правильном направлении - по возможности вкладывать частные инвестиции в предприятия, производящие инновационную технику и оборудование для АПК в качестве повышения и их инновационной составляющей, что было бы заманчиво, прежде всего, для малых хозяйствующих субъектов. При всём том, инновационные проекты должны быть экологичными, ресурсообеспеченными, должны строиться с учётом российской экономической специфики, что при совокупности с иными мероприятиями даст возможность добиться максимального эффекта от их осуществления. Однако, реально реализовать программу, скорее всего, возможно путём десятикратного роста годового объёма производства техники.

С этой точки зрения следует использовать преиму- щества крупных агропромышленных структур для развития отечественного АПК [15], однако одновременно необходимо создавать для этого условия и для развития мелких и средних форм на селе - некие координированные структуры, которые смогли бы реализовывать партнёрство мелкого и крупного аграрного бизнеса [16]. Не снята с повестки дня и необходимость развития инфраструктуры села, что, возможно, усилит внутреннюю миграцию населения из городов, и что поможет преодолеть кризис АПК [17].

Необходимо подчеркнуть, что обострившаяся экономическая ситуация, вызванная санкционной политикой коллективного Запада, показала насущную потребность в опережающем независимом развитии отечественных предприятий, производящих инновационную технику и оборудование для АПК, формирования их преимуществ на конкурентном поле, что предполагает, прежде всего, охват новых и новых рынков для наращивания своей доли, прироста объёмов выпускаемой продукции, ретрективности получения прибыли на длительную перспективу.

Представляется, что, объединяясь в группы, предприятия создадут критическую массу для разносторонних конкурентных достижений. Несомненно, важно не приостанавливать технологическое обновление предприятий АПК. Имеет ценность, что анализируемые тракторные заводы, как и ряд других предприятий смогли реализовать свою инновационную продукцию, что позволило аграриям добиться урожайности до 26 ц/га в среднем на площади посевов в 47,6 млн га, а валовых сборов - до 125 млн тонн. Так, обзор рынка свинины показывает, что в 2019 г. на базе крупных сельхозпредприятий произведено 3,9 млн тонн свинины в убойном весе [18], товарного молока - 250,7 тыс. тонн [19]. Произведено 120,6 млн т. зерна [20].

Для достижения более высоких результатов в развитии предприятий АПК важно добиваться, чтобы он стал конкурентоспособным передовым сектором отечественной экономики, а отраслевая стратегия должна исходить из реализации долгосрочных проектов, ориентироваться на перспективное развитие. Предприятия, производящие инновационную технику и оборудование для АПК, ориентированы на непрерывность инвестиционного процесса, технологические инновации, которые обеспечивают перспективы инновационного развития [21].

\section{ЛИТЕРАТУРА}

1. «0 мерах по реализации государственной научно-технической политики в интересах развития сельского хозяйства» [Текст] / Указ Президента РФ от 21 июля 2016 г. № 350; «0 стратегии научно-технологического развития Российской Федерации // Указ Президента РФ от 01 декабря 2016 г. № 642; Феде- 
ральная научно-техническая программа развития сельского хозяйства на период до 2025 г. / base.garant.ru

2. Состояние и перспективы развития производства сельхозтехники в РФ. - М.: Россспецмаш, 2019. - С.11.

3. Итоговый доклад о результатах деятельности Минсельхоза России за 2019 год. - М., 2019. - С.4.

4. аненко, И. Инвестиции опять сменили драйверы // АгроИнвестор. - № 12 (143). - 2019.

5. Сельское хозяйство в России. 2019: Стат. сб./ Росстат - М., 2019. - С.32.

6. Бурак П.И. и др. Состояние и перспективы обновления парка сельскохозяйственной техники. Научный аналитический 0бзор. - М.: МСХ РФ, 2019. - С.7.

7. Дятловская, Е. Обеспеченность аграриев тракторами в 2018 году вновь снизилась // Агроинвестор. 18 апреля 2019 г.

8. Стратегия развития сельскохозяйственного машиностроения России на период до 2030 года. - C. 10. // strategy_tll_2030.pdf

9. «Состояние и перспективы развития производства сельхозтехники в Российской Федерации». - М.: Россспецмаш, 2019. - С. 10.

10. Тихомиров Д.А., Трунов С.С., Ламонов Н.Г. Методика расчёта термоэлектрической установки для осушения воздуха // Инновации в сельском хозяйстве. 2019. - № 3 (32). - С.261-271.

11. Тихомиров Д.А., Трунов С.С., Ламонов Н.Г. Термоэлектрическая установка осушения воздуха помещений сельскохозяйственного назначения // Агротехника и энергообеспечение. - 2019. № 2 (23). - С.27-35.

12. Тихомиров Д.А., Кузьмичёв А.В., Трунов С.С. Тепловые завесы в системах микроклимата животноводческих ферм // Электротехнологии и электрооборудование в АПК. - 2019. - № 1 (34). - С. 14-20.

13. Состояние и перспективы развития производства сельхозтехники в Российской Федерации. - М.: Россспецмаш, 2019. - С.15.

14. Кузьмин В. В России планируют вовлечь в сельхозоборот 12 млн га неиспользуемой земли // Российская газета. 30.09. 2020.

15. Миндлин Ю.Б. Формирование и развитие инновационных кластеров в России (на примере АПК) // Современная наука: актуальные проблемы теории и практики. Серия: Экономика и право. - 2019. - № 5. - С.43-48.

16. Миндлин Ю.Б. Инновационное развитие АПК в России на основе интеграционных процессов кластеризации // Современная наука: актуальные проблемы теории и практики. Серия: Экономика и право. - 2019. - № 6. - С.52-57.

17. Никифоров, Л.В. Социально-экономическая интеграция города и села (содержание, цели, пути, условия) [Текст] // Л.В. Никифоров. - М.: Наука, 1988. $287 \mathrm{c}$.

18. agrovesti.net

19. marketing.rbc.ru

20. rambler.ru

21. Лисейкина 0.В. Инвестиционное обеспечение инновационных процессов в животноводстве // Вестник Всероссийского научно-исследовательского института механизации животноводства. - 2014. - № 3 (15). - С. 130-132.

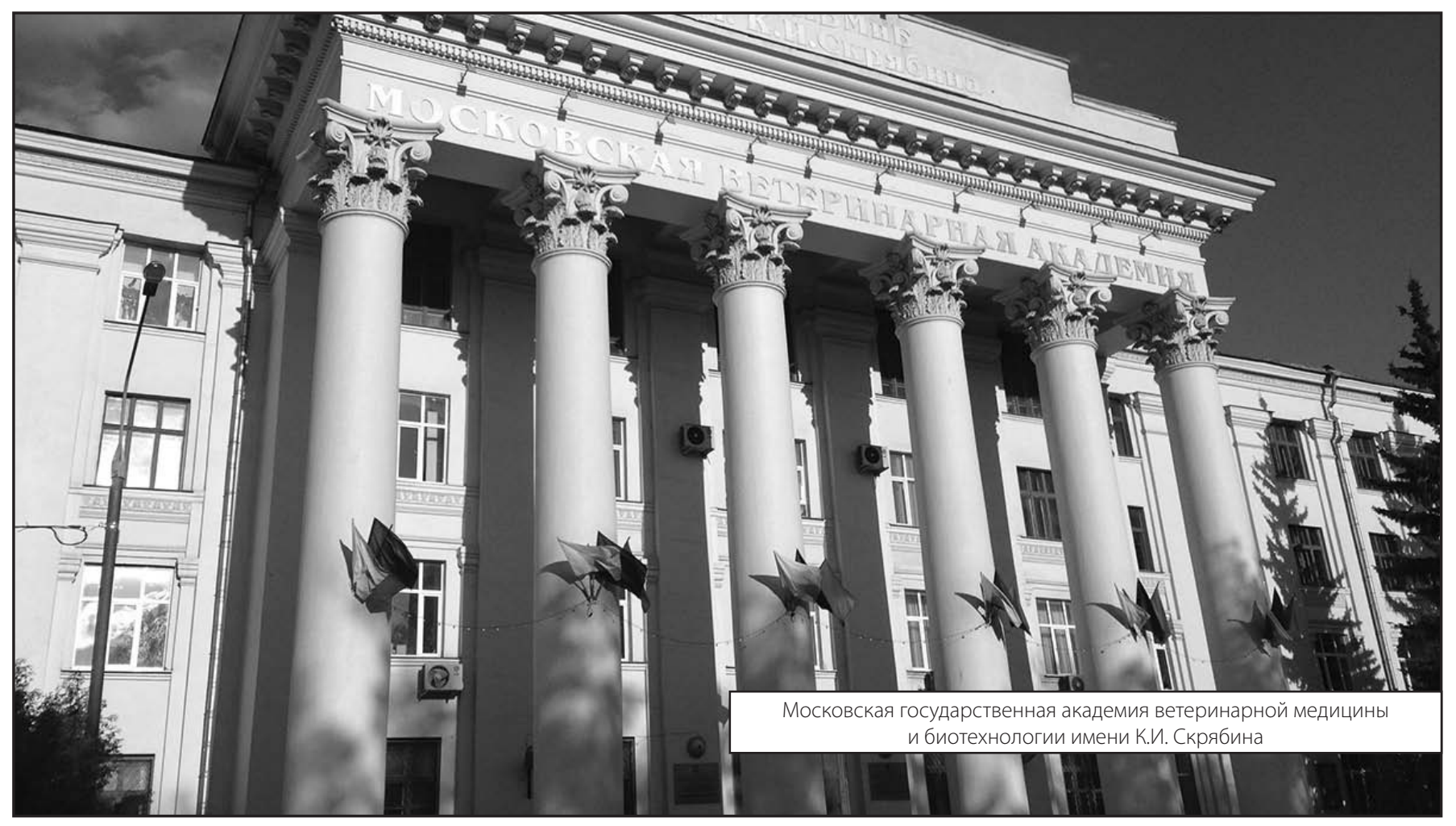

